\title{
NOTES
}

\section{Activation of the Complement System in Blood on the Surface of Segmented Polyurethaneurea Having Good Blood Compatibility}

\author{
Yuko IKeda, Shinzo KohjIYA, Shinzo Yamashita, \\ Hiroshi Fukumura, * and Susumu YoshikaWA* \\ Department of Chemistry, Kyoto Institute of Technology, \\ Matsugasaki, Kyoto 606, Japan \\ ${ }^{*}$ Government Industrial Research Institute, Osaka, Midorigaoka, \\ Ikeda, Osaka 563, Japan
}

(Received October 5, 1987)

KEY WORDS Polyurethaneurea Biocompatibility /
Recently complement activation was reported to be one of the factors influencing biocompatibility of polymeric materials for biomedical purposes. ${ }^{1-5}$ For example, two of the present authors (Fukumura and Yoshikawa) showed that the higher the degree of grafting of poly( $N$-vinylpyrrolidone) onto polyethylene, the larger was the complement activation. ${ }^{5)}$ However, the papers in this area are still scarce and, it is to be elucidated whether the complement activation can induce thrombogenesis on the surface of polymeric materials.

In this report, we employ segmented polyurethaneurea synthesized from the prepolymers whose oxyethylene-units contents are 0 , $33,62 \mathrm{~mol} \%$ of oxytetramethylene units, as samples for the evaluation of complement activation ability in a in vitro complement system of human serum. The results are compared with their antithrombogenicities. These polyurethaneureas were shown to have good antithrombogenicity as well as good mechanical properties. ${ }^{6-8}$

\section{EXPERIMENTAL}

\section{Materials}

The chemical structures of the polyurethaneureas are shown in Figure 1, and the sample codes are given in Table I together with some molecular properties of the prepolymers. The preparation methods of these polymers were described in the previous papers. ${ }^{6,8}$

\section{In Vitro Evaluation}

The samples were subjected to the LeeWhite blood-clotting test and the complement activation test. The Lee-White method is now a popular in vitro evaluation method using whole human blood, and the results were shown by the clotting time index (CTI) ${ }^{6,8}$ The larger CTI means better blood compatibility.

In the complement activation test, the glass beads coated with the sample polymer were used. ${ }^{9}$ The procedures are shown in Figure 2. Glass beads (Nippon Chromato Co.; meshed and collected the beads between 48 and 60 mesh, the diameter ca. $270 \mu \mathrm{m})$ were soaked in the polymer solution $(0.5 \mathrm{wt} \%$ polymer in dimethylacetoamide). After filtration, the beads 


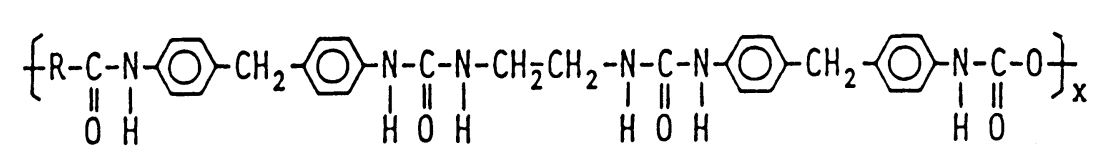

Soft Segment

Hard Segment

$$
\begin{aligned}
& \mathrm{R}: \quad+\mathrm{CH}_{2} \mathrm{CH}_{2} \mathrm{CH}_{2} \mathrm{CH}_{2} \mathrm{O}_{\mathrm{m}} \\
& \left.\left.+\mathrm{CH}_{2} \mathrm{CH}_{2} \mathrm{O}\right)_{n} \mathrm{CH}_{2} \mathrm{CH}_{2} \mathrm{CH}_{2} \mathrm{CH}_{2} \mathrm{O}\right)_{\text {m }} \mathrm{CH}_{2} \mathrm{CH}_{2} \mathrm{O}+_{\mathrm{n}} \\
& \text { Predolymer : } \left.\quad \mathrm{HO}_{\mathrm{C}} \mathrm{CH}_{2} \mathrm{CH}_{2} \mathrm{CH}_{2} \mathrm{CH}_{2} \mathrm{O}\right)_{-} \mathrm{H} \\
& \left.\mathrm{HOHCH}-\mathrm{CH}_{2} \mathrm{O}+{ }_{n}^{-} \mathrm{CH}_{2} \mathrm{CH}_{2} \mathrm{CH}_{2} \mathrm{CH}_{2} \mathrm{O}\right)_{-} \mathrm{CH}_{2} \mathrm{CH}_{2} \mathrm{O}{ }_{n} \mathrm{H} \quad \text { (HT-ETE) } \\
& \text { Dilsocyonate : } \quad \mathrm{OCN} \text {-0 - } \mathrm{CH}_{2} \text { - } \\
& \text { Choin extender : } \mathrm{H}_{2} \mathrm{~N}-\mathrm{CH}_{2} \mathrm{CH}_{2}-\mathrm{NH}_{2}
\end{aligned}
$$

Figure 1. Chemical structure of segmented polyurethaneurea.

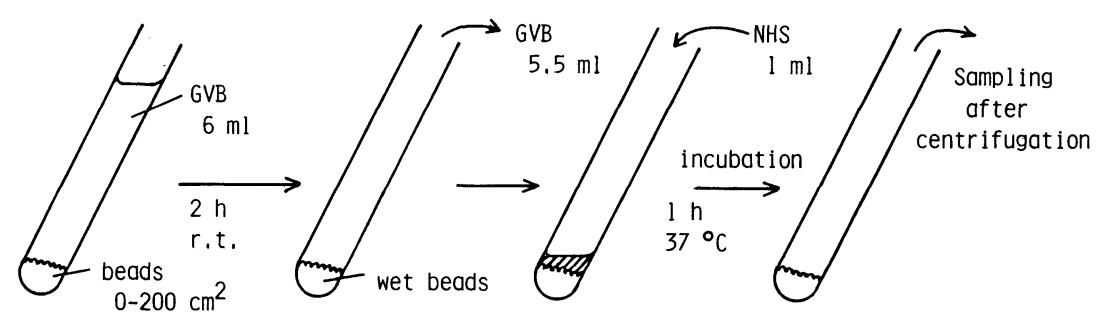

Figure 2. Experimental procedures for complement activation in normal human serum by the beads method.

Table I. Polyurethaneurea samples

\begin{tabular}{lccc}
\hline & \multicolumn{3}{c}{ Prepolymer } \\
\cline { 2 - 4 } Sample code & & & OE content \\
& $\bar{M}_{n}{ }^{\mathrm{a}}$ & $\bar{M}_{w} / \bar{M}_{n}^{\mathrm{b}}$ & $\mathrm{mol} \%$ \\
\cline { 3 - 4 } & & & 0 \\
SPUU & 1830 & 1.45 & 12 \\
SEUU-1 & 2090 & 1.44 & 22 \\
SEUU-2 & 2180 & 1.53 & 33 \\
SEUU-3 & 2430 & 1.46 & 62 \\
SEUU-4 & 4040 & 1.27 & \\
\hline
\end{tabular}

a Number-average molecular weight by vapor pressure osmometry.

b $\bar{M}_{w}$ is weight-average molecular weight, and the ratio was determined by GPC.

c Oxyethylene-units content determined by ${ }^{1} \mathrm{H}$ NMR.

were kept at $60^{\circ} \mathrm{C}$ to evaporate the solvent. This coating procedure was repeated three times and finally subjected to drying under a reduced pressure at room temperature before use. The beads were immersed in gelatin veronal buffer (GVB) for two hours at room temperature, and mixed with normal human serum (NHS). The mixture (the ratio, surface area of the beads $/ \mathrm{NHS}=200 \mathrm{~cm}^{2} / \mathrm{ml}$ ) were incubated at $37^{\circ} \mathrm{C}$ for one hour. $\mathrm{CH}_{50}$, i.e., $50 \%$ hemolytic unit of complement, of the serum after the contact with polymer coated beads was assayed according to the method of Mayer. ${ }^{10)}$ As a reference, $\mathrm{CH}_{50}$ of the serum without mixing with the beads was measured, and the decrease of $\mathrm{CH}_{50}$ is calculated as follows

Decrease of $\mathrm{CH}_{50}(\%)$

$$
=\frac{\mathrm{CH}_{50}(\text { reference })-\mathrm{CH}_{50}(\text { polymer })}{\mathrm{CH}_{50}(\text { reference })} \times 100
$$




\section{RESULTS AND DISCUSSION}

The observation of the surface of coated beads by a scanning electron microscope (Akashi MINI-SEM) assured homogeneity of coating. The surface area $v s$. amount of NHS ratio was fixed to $200 \mathrm{~cm}^{2} / \mathrm{ml}^{9,11}$ These factors are important to obtain reproducible results in complement activation. ${ }^{11}$

Figure 3 shows the values of CTI and the decrease of $\mathrm{CH}_{50}$ for three polyurethaneureas as a function of oxyethylene-units content in the prepolymers. Incorporation of oxyethylene units improved the in vitro antithrombogenicity of polyurethaneurea based on poly (oxytetramethylene) as judged from the CTI values. However, $62 \mathrm{~mol} \%$ of oxyethylene units seems to be too much. On the other hand, the remaining activity of $\mathrm{CH}_{50}$ decreased with oxyethylene-units content. In other words, the antithrombogenicity is improved, but the complement activation is increased with the introduction of oxyethylene units. The activation of complement system is estimated to be responsible for generation of cleavage products that cause migration of leucocytes, ${ }^{12)}$ and haemodialysis leucopenia. ${ }^{13}$

In Table II are shown the decreases of $\mathrm{CH}_{50}$ of various polymers including the present results on polyurethaneureas. Both polyethylene and SPUU were found to be inactive. Here, SPUU is a polyurethaneurea based on poly (oxytetramethylene) prepolymer. The more the oxyethylene units in SEUU or the more the vinyl alcohol units in EVAL, the more is the complement activation. Polarity of the polymer may influence on the activation of complement system in blood. However, the decrease of $\mathrm{CH}_{50}$ of two SEUUs was much less than that of EVAL, the ethylene content of which was $32 \%$. This EVAL is now utilized in a dialyzer. Therefore, it seems to be justifiable to say that the extent of complement activation of SEUUs is not too much as to annul their good blood compatibilities.

It is known that two processes, i.e., the

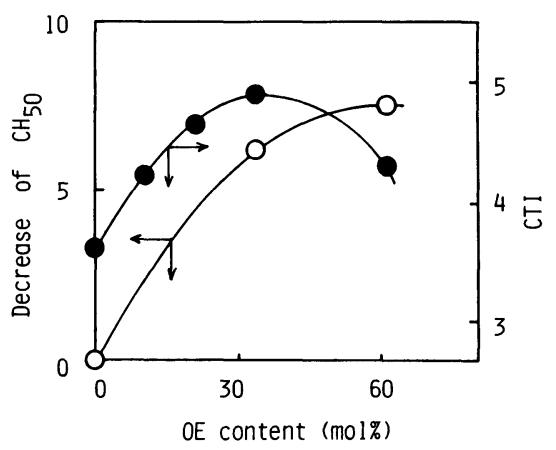

Figure 3. Oxyethylene-units content dependency of complement activation and clotting time index in segmented polyurethaneureas.

Table II. Complement activation ${ }^{\text {a }}$ by various polymers

\begin{tabular}{|c|c|c|}
\hline \multirow{2}{*}{ Sample } & \multirow{2}{*}{ (Remark) } & Decrease of $\mathrm{CH}_{50}$ \\
\hline & & $\%$ \\
\hline SPUU & $\left(\mathrm{OE},^{\mathrm{b}} \quad 0 \mathrm{~mol} \%\right)$ & 0 \\
\hline SEUU-3 & $\left(\mathrm{OE},{ }^{\mathrm{b}} 33 \mathrm{~mol} \%\right)$ & 6.2 \\
\hline SEUU-4 & $\left(\mathrm{OE},{ }^{\mathrm{b}} 62 \mathrm{~mol} \%\right)$ & 7.5 \\
\hline Polyethylene & & $0^{\mathrm{d}}$ \\
\hline EVAL- $65^{c}$ & (Ethylene, $65 \%$ ) & $9^{d}$ \\
\hline EVAL-32 ${ }^{c}$ & (Ethylene, $32 \%$ ) & $35^{\mathrm{d}}$ \\
\hline Cellulose & & $38^{\mathrm{d}}$ \\
\hline
\end{tabular}

a Measured by the beads method.

b Oxyethylene unit.

c Ethylene-vinyl alcohol copolymer.

d Taken from the literature. ${ }^{9}$

classical and the alternative passways participate in the activation. ${ }^{10,11}$ Both or either passway can work in the activation on the surfaces of synthetic polymers. ${ }^{9)}$ Mechanistic studies and in vivo evaluation of complement activation $^{6}$ on SEUU remain to be investigated in order to elucidate the relationship between complement activation and thrombogenesis further.

Acknowledgement. This work was supported in part by a Grant-in-Aid for Scientific Research (No. 60550640) from the Ministry of Education, Science, and Culture of Japan. 


\section{Y. IKEDA et al.}

\section{REFERENCES}

1. C. L. Van Kampen and D. F. Gibbons, J. Biomed. Mater. Res., 13, 517 (1973).

2. G. A. Herzlinger and R. D. Cumming, Trans. Am. Soc. Artif. Intern. Organs, 26, 165 (1980).

3. C. A. Ward, A. Koheil, W. R. Johnson, and P. N. Madras, J. Biomed. Mater. Res., 18, 255 (1984).

4. V. I. Sevastianov and E. A. Tseytlina, J. Biomed. Mater. Res., 18, 969 (1984).

5. H. Fukumura, K. Hayashi, S. Yoshikawa, M. Miya, N. Yamamoto, and I. Yamashita, Biomaterials, 8, 74 (1987).

6. Y. Ikeda, S. Kohjiya, S. Yamashita, N. Yamamoto, K. Hayashi, and I. Yamashita, Nippon Kagaku Kaishi, 699 (1986).

7. S. Kohjiya, Y. Ikeda, S. Yamashita, K. Hayashi, N. Yamamoto, and I. Yamashita, Nippon Gomu Kyokaishi, 59, 685 (1986).
8. S. Kohjiya, Y. Ikeda, and S. Yamashita, "Polyurethanes in Biomedical Engineering II," by $\mathrm{H}$. Plank et al. Ed., Elsevier, Amsterdam, 1987, p 183.

9. H. Fukumura, S. Yoshikawa, and M. Miya, Preprints of the 14th Symposium on Biomedical Polymers, 1985, p 75.

10. M. M. Mayer, "Experimental Immunology," E. A. Kabat and M. M. Mayer, Ed., Charles C. Thomas Publishers, Springfield, Ill., 1961,'p 133.

11. S. Yoshikawa, H. Fukumura, M. Miya, Y. Akagaki, and S. Inai, Proceedings of the 21st Complement Symposium, the Japanese Association for Complement Research, 1984, Osaka, p 19.

12. H. J. Muller-Eberhard, Am. Rev. Biochem., 44, 697 (1975).

13. P. R. Craddock, J. Fehr, A. P. Dalmasso, K. L. Brigham, and H. S. Jacob, J. Clin. Invest., 59, 879 (1977). 